\title{
Feeding frequency for lactating cows: diurnal patterns of hormones and metabolites in peripheral blood in relation to milk-fat concentration
}

\author{
By J. D. SUTTON, I. C. HART $\dagger$, S. V. MORANT $\ddagger$, E. SCHULLER \\ AND A. D. SIMMONDS \\ National Institute for Research in Dairying, Shinfield, Reading*
}

(Received 26 February 1988 - Accepted 11 April 1988)

\begin{abstract}
1. The present paper reports the effects of dietary modifications on the diurnal pattern of concentrations of certain metabolites and hormones in the peripheral blood of lactating dairy cows. The cows were given fixed rations of hay and high-cereal concentrates in the proportions of 30:70 or 10:90 (w/w). The concentrates were given in either two or six equal meals daily; the hay was given twice daily.

2. Previous reports of the same experiment had shown that milk-fat yield and concentration were reduced by increasing the proportion of concentrates in the diet and increased by more frequent feeding of the concentrates. These changes could be explained in part by changes in rumen volatile fatty acid (VFA) proportions and mean daily concentrations of VFA, particularly propionic acid, and insulin in the peripheral blood, but these factors failed to explain all the increase in milk-fat concentration caused by more frequent feeding.

3. Analysis of blood samples taken at hourly intervals for $24 \mathrm{~h}$ at two stages of lactation showed that, in the cows fed six times daily, the concentrations of metabolites and hormones remained relatively constant over the day. In the cows fed twice daily, the concentrations of VFA, 3-hydroxybutyric acid and insulin all increased after both meals whereas the concentrations of glucose and growth hormone tended to fall. The concentration of nonesterified fatty acids tended to increase overnight and fall rapidly after the morning feed. The concentrations of glucagon, thyroxine and prolactin showed no clear pattern in relation to meals. The postprandial responses of propionate, insulin and growth hormone were greater with the higher concentrate diet.

4. The maximum concentration and the diurnal range of concentrations were reduced by more frequent feeding of both diets in the case of propionic acid and of the higher concentrate diet in the case of insulin, but the effects on insulin concentrations of more frequent feeding of the lower concentrate diet were smaller and not significant. The maximum concentration and the diumal range of concentrations of growth hormone were unaffected by meal frequency.

5. It is concluded that the severity of milk-fat depression in cows fed twice daily is increased by the rapid rise in propionic acid concentration in the peripheral blood after a meal, which in turn increases insulin secretion and may be accompanied by a suppression of growth hormone release. This causes lipogenesis to be diverted towards adipose tissue at the expense of the mammary gland. In cows fed more frequently, VFA absorption is more evenly spread over the day and is not closely associated with changes in insulin or growth hormone concentrations.
\end{abstract}

The milk-fat depression caused by giving dairy cows large amounts of starchy concentrates in two meals daily can be markedly alleviated if the number of meals of the same daily ration of concentrates is increased to six or more (Sutton et al. 1985). The change in the molar proportions of volatile fatty acids (VFA) in the rumen with more frequent feeding (Sutton et al. 1986) was found to be much smaller than would be expected if this was the principal cause of the increase in milk-fat concentration, as had been proposed by Kaufmann et al. (1975). Another factor associated with milk-fat depression is elevated plasma insulin. It has been proposed that the increase in plasma insulin concentrations usually found with low-roughage diets increases lipogenesis in adipose tissue, thereby reducing milk-fat synthesis (Annison, 1976). Associated with these changes, reductions in the entry rate of palmitic acid into the peripheral system and in the uptake by the udder

* Now AFRC Institute for Grassland and Animal Production, Hurley Research Station, Hurley, Maidenhead, Berks, SL6 5LR.

Present addresses † American Cyanamid Company, Agricultural Research Division, Princeton, NJ 08540, USA. $\ddagger$ Milk Marketing Board, Thames Ditton, Surrey KT7 0EL. 
of acetate, 3-hydroxybutyrate (3HBA) and triglycerides have been found (Annison et al. 1974).

In the present experiments, more frequent feeding of the most extreme diet, containing $900 \mathrm{~g}$ concentrate $/ \mathrm{kg}$ diet, led to a reduction of about $50 \%$ in the mean daily concentration of plasma insulin in jugular blood which appeared to provide an additional explanation for the increased milk-fat concentration. However, with the diet containing $700 \mathrm{~g}$ concentrate/ $\mathrm{kg}$ diet, milk-fat concentration was increased by $6.6 \mathrm{~g} / \mathrm{kg}$ by more frequent feeding yet the concentration of plasma insulin was unchanged. It was concluded that additional control mechanisms must be sought to explain the response of milk-fat concentrations. It seemed likely that the twice daily feeding routine would lead to greater fluctuations in certain metabolites and hormones in the blood, particularly those derived from or affected by VFA production in the rumen. The present paper therefore reports more detailed analysis of the samples from the experiment described earlier to examine changes over the day in the concentrations of the principal metabolites and hormones.

\section{EXPERIMENTAL}

The main details of the experiment were reported earlier (Expt 3 in Sutton et al. 1985, 1986) but the more important aspects are repeated below.

Sixteen Friesian cows were given either $5.0 \mathrm{~kg}$ hay and $11.5 \mathrm{~kg}$ concentrates $(700 \mathrm{~g}$ concentrates $/ \mathrm{kg}$ ) or $1.6 \mathrm{~kg}$ hay and $14.0 \mathrm{~kg}$ concentrates $(900 \mathrm{~g}$ concentrates $/ \mathrm{kg}$ ) for weeks 5-27 of lactation. Half the cows were given their feed in two equal meals at 06.00 and 14.30 hours and the other half were given their hay in two meals at 06.00 and 16.45 hours and their concentrates every $4 \mathrm{~h}$ in six equal portions starting at 06.30 hours. The concentrates contained about $700 \mathrm{~g}$ barley $/ \mathrm{kg}$ and had a crude protein (nitrogen $\times 6.25$ ) concentration of 220 (700 g concentrate $/ \mathrm{kg}$ diet) or $204(900 \mathrm{~g}$ concentrate $/ \mathrm{kg}$ diet $) \mathrm{g} / \mathrm{kg}$ dry matter. Digestible energy intakes were very similar, varying from 181 to $190 \mathrm{MJ} / \mathrm{d}$ for the four treatments. At weeks 6 (early lactation) and 22 (mid-lactation), blood samples were taken every hour for $24 \mathrm{~h}$ by means of an indwelling jugular catheter. Methods of processing and analysing the samples were described previously (Sutton et al. 1986). All the samples were analysed for glucose and the hormones but because of the small amount of sample remaining, samples were bulked across cows within treatments for each sample time and re-analysed for VFA, non-esterified fatty acids (NEFA) and 3HBA.

\section{Statistical methods}

For the hormones and glucose, analyses of variance were carried out for the following derived variates: daily concentration, minimum and maximum daily concentrations, the range of concentrations (maximum-minimum) in each animal on each day. Treatment effects were tested using standard error of differences between means at the same stage of lactation, based on error mean squares for variation between animals $(12 \mathrm{df})$ and for animal $\times$ stages of lactation interactions $(12 \mathrm{df})$. Values for the mean daily concentration were reported previously (Sutton et al. 1986).

Because samples were pooled over animals on the same treatment combination for the remaining metabolites, no estimates of error were available to provide tests of significance.

All statistical analyses were carried out in natural units and in logarithmic units in which there is greater homogeneity of variance. The two sets of analyses yielded very similar results with only minor differences in the level of significance for some comparisons. For ease of presentation, all the results presented in the present paper are derived from analysis of untransformed data. 
Table 1. Molar proportions of the principal volatile fatty acids (VFA) (mmol/mol total VFA) in the rumen and milk yield and fat production during weeks 7-27 of lactation (from Expt 3 Sutton et al. 1985, 1986)

\begin{tabular}{|c|c|c|c|c|c|}
\hline \multirow{2}{*}{$\begin{array}{l}\text { Concentrates:hay }(w / w) \ldots \\
\text { No. of meals/d... }\end{array}$} & \multicolumn{2}{|c|}{$70: 30$} & \multicolumn{2}{|c|}{$90: 10$} & \multirow[b]{2}{*}{ SEM } \\
\hline & 2 & 6 & 2 & 6 & \\
\hline \multicolumn{6}{|l|}{ Rumen VFA } \\
\hline Acetic & 646 & 654 & 532 & 561 & 17.5 \\
\hline Propionic & 172 & 163 & 289 & 275 & 20.7 \\
\hline n-Butyric & 128 & 138 & 114 & 107 & $10 \cdot 4$ \\
\hline \multicolumn{6}{|l|}{ Milk } \\
\hline Yield $(\mathrm{kg} / \mathrm{d})$ & $19 \cdot 7$ & $20 \cdot 2$ & $23 \cdot 0$ & $21 \cdot 4$ & 1.42 \\
\hline Fat concentration $(\mathrm{g} / \mathrm{kg})$ & 32.6 & $39 \cdot 2$ & 17.9 & $29 \cdot 7$ & 2.01 \\
\hline Fat yield $(\mathrm{kg} / \mathrm{d})$ & 0.64 & 0.79 & 0.42 & 0.62 & 0.055 \\
\hline
\end{tabular}

\section{RESULTS}

The molar proportions of the principal VFA in the rumen, milk yield and milk-fat yield and concentration in the cows during weeks 7-27 of lactation, published previously (Sutton $e t$ al. 1986), are summarized in Table 1 . When the cows were given their concentrates twice daily, milk-fat concentration was quite low with the diet containing $700 \mathrm{~g}$ concentrates $/ \mathrm{kg}$ diet. Increasing the concentrates to $900 \mathrm{~g} / \mathrm{kg}$ diet caused even more severe milk-fat depression which was associated with a lower proportion of acetic acid and higher proportion of propionic acid in the rumen VFA. When the concentrates were given in six meals daily, milk-fat yield and concentration were increased with both diets but the changes in rumen VFA proportions were small and not significant.

Mean daily concentrations of metabolites and hormones in jugular blood at the two stages of lactation were published previously (Sutton et al. 1986). Absolute concentrations of some of these, notably glucose, NEFA, prolactin, growth hormone and insulin, were significantly affected by stage of lactation. However, no significant interactions between stage of lactation and feeding frequency or diet type for any of the measures of the concentrations of metabolites or hormones were found in the present analysis, and the daily patterns of the concentrations of the metabolites and hormones are therefore presented for week 22 of lactation only (Figs. 1 and 2).

\section{Blood metabolites}

The results for the metabolites must be treated with some caution because the need to bulk samples before analysis for all the metabolites except glucose precluded any statistical analysis.

There was a tendency for the concentration of plasma glucose to fall after feeding in the groups fed twice daily (Fig. 1). Feeding frequency had no effect on the minimum or maximum concentrations or on the range. Both minimum $(P<0.01)$ and maximum $(P<0.001)$ values, but not the range, were higher on the higher concentrate diet. On highand low-concentrates, average minimum concentrations were 3.47 and 2.89 (SE 0.122 ) $\mathrm{mmol} / \mathrm{l}$ respectively and maximum concentrations were 4.56 and 3.80 (SE $0 \cdot 100$ ) $\mathrm{mmol} / \mathrm{l}$ respectively.

With twice daily feeding of the higher concentrate diet and, in early lactation only, of the lower concentrate diet, the concentration of NEFA rose steadily overnight and fell rapidly after the morning meal (Fig. 1). With frequent feeding the concentration was relatively 
(a) $900 \mathrm{~g}$ concentrates $/ \mathrm{kg}$

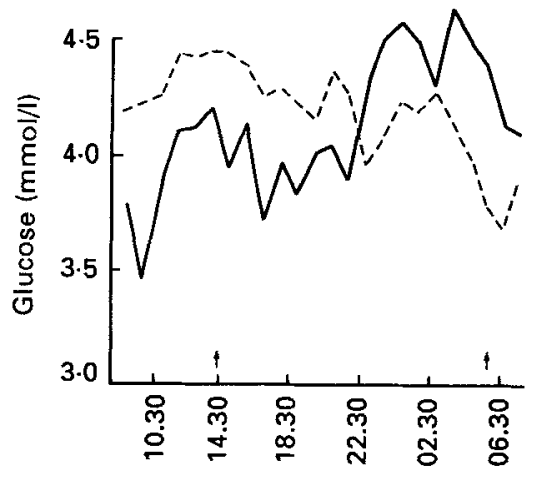

Time of day (hours)

(b) $900 \mathrm{~g}$ concentrates $/ \mathrm{kg}$

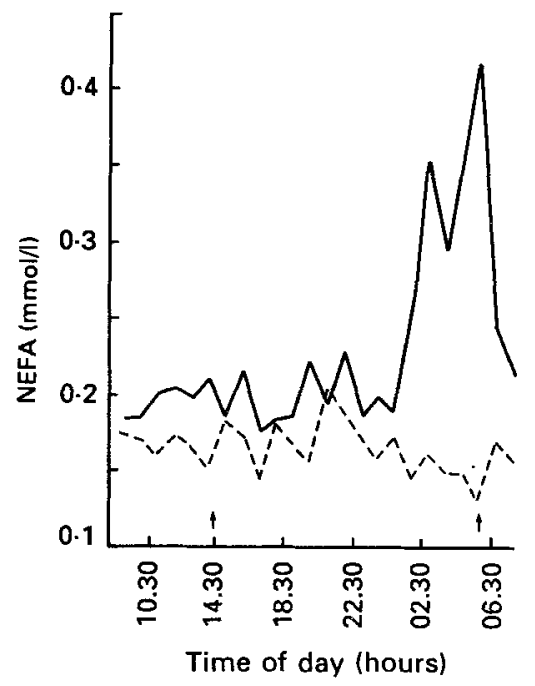

(c) $900 \mathrm{~g}$ concentrates $/ \mathrm{kg}$

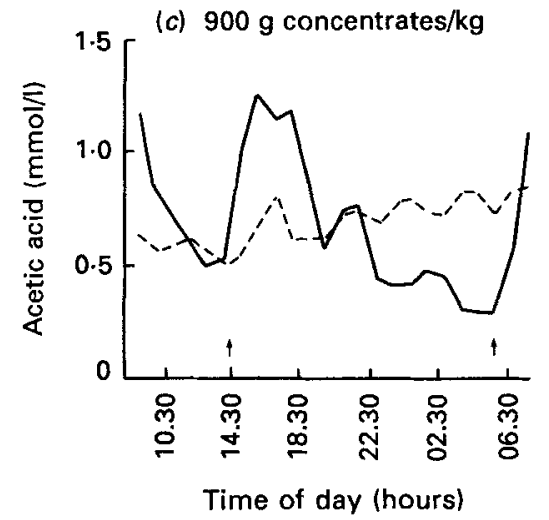

(a) $700 \mathrm{~g}$ concentrates $/ \mathrm{kg}$

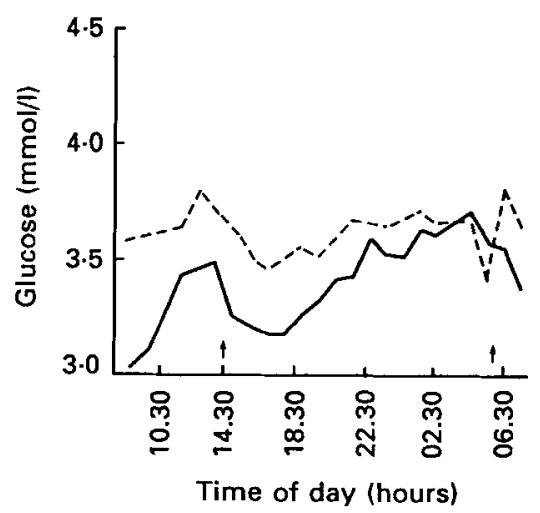

(b) $700 \mathrm{~g}$ concentrates $/ \mathrm{kg}$
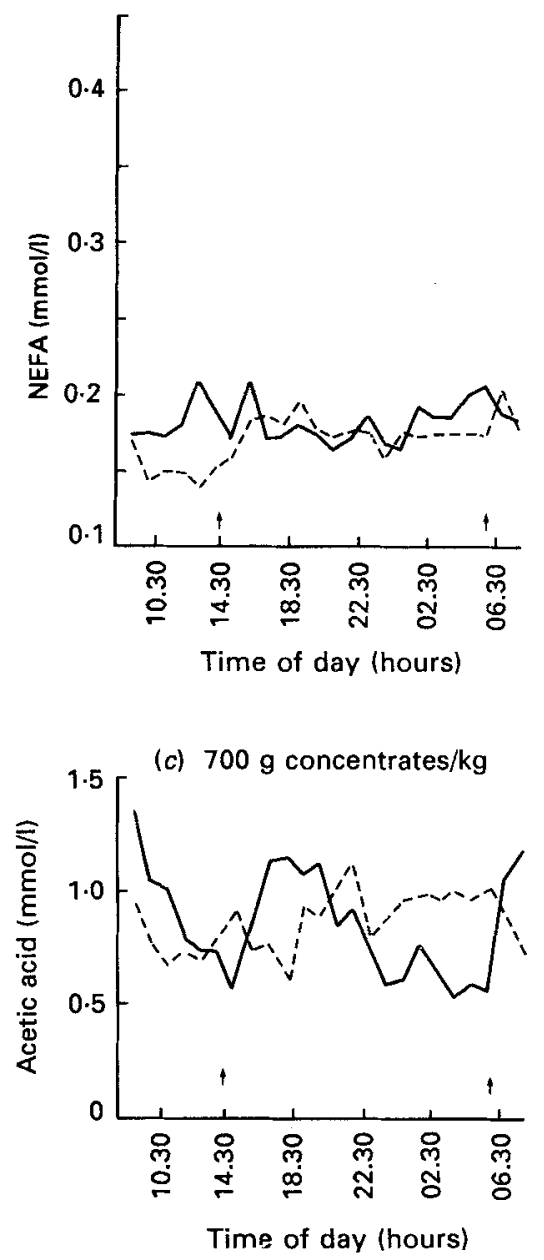

Fig. 1. For caption, see facing page. 

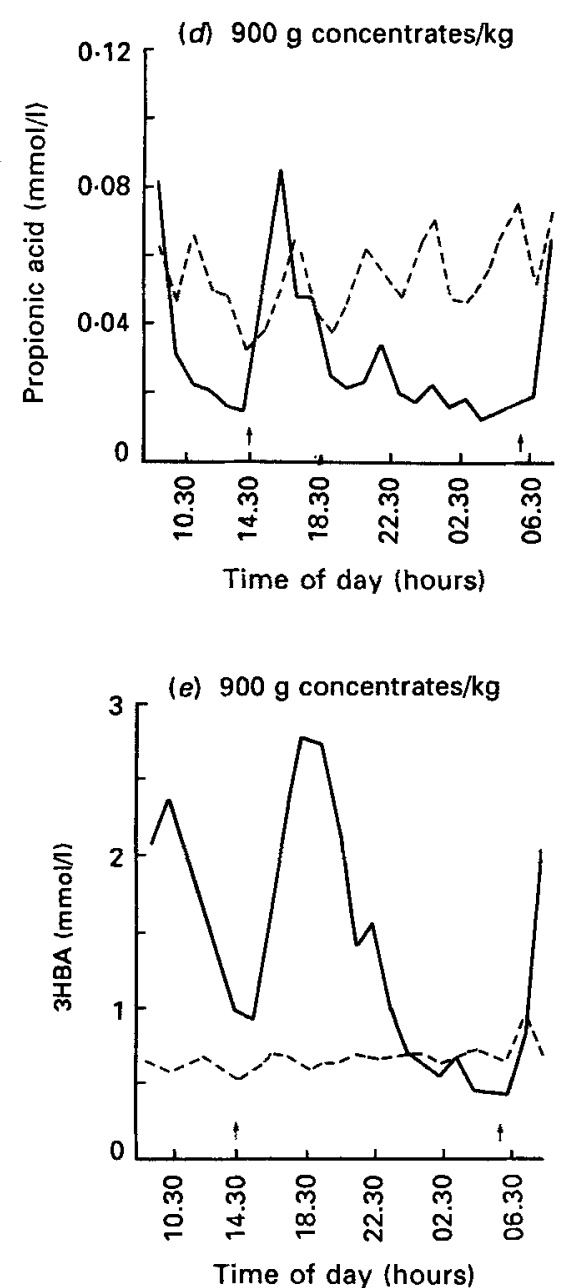
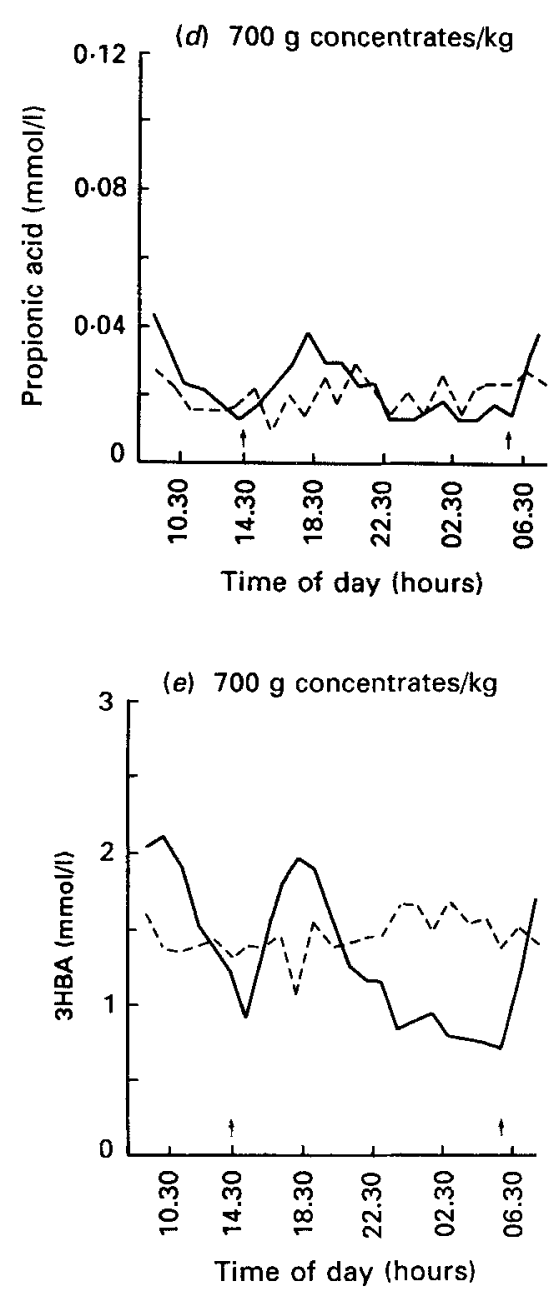

Fig. 1. Concentrations over $24 \mathrm{~h}$ of certain metabolites measured at about week 22 of lactation in the jugular blood of lactating cows given two diets $(900$ or $700 \mathrm{~g}$ concentrates $/ \mathrm{kg}$ ) twice daily ( $\longrightarrow$ ) or in six meals daily (---), (a) Glucose, (b) non-esterified fatty acids (NEFA), (c) acetic acid, (d) propionic acid, (e) 3-hydroxybutyric acid (3HBA). Feeding times are shown for six times daily feeding on the $x$ axis and for twice-daily feeding as arrows. Results are the means for four cows per treatment.

constant. The maximum concentration and the range were higher with twice daily feeding than with frequent feeding for the higher concentrate diet and, in early lactation only, for the lower concentrate diet also.

In cows fed twice daily, the concentration of acetic acid, propionic acid and 3HBA showed a very similar pattern over the day with maximum values being attained about 3-4 h after each meal (Fig. 1). With more frequent feeding, peaks of concentration of acetic acid and propionic acid, but not of 3HBA, occurred about $2 \mathrm{~h}$ after each meal with the higher concentrate diet but not with the lower concentrate diet. With the higher concentrate diet, the minimum concentrations of acetic and propionic acids and 3HBA were higher with more frequent feeding but the maximum concentrations and, hence, the daily range were both lower. With the lower concentrate diet, the tendencies were similar although less pronounced. With twice daily feeding, the maximum concentration of propionic acid was 

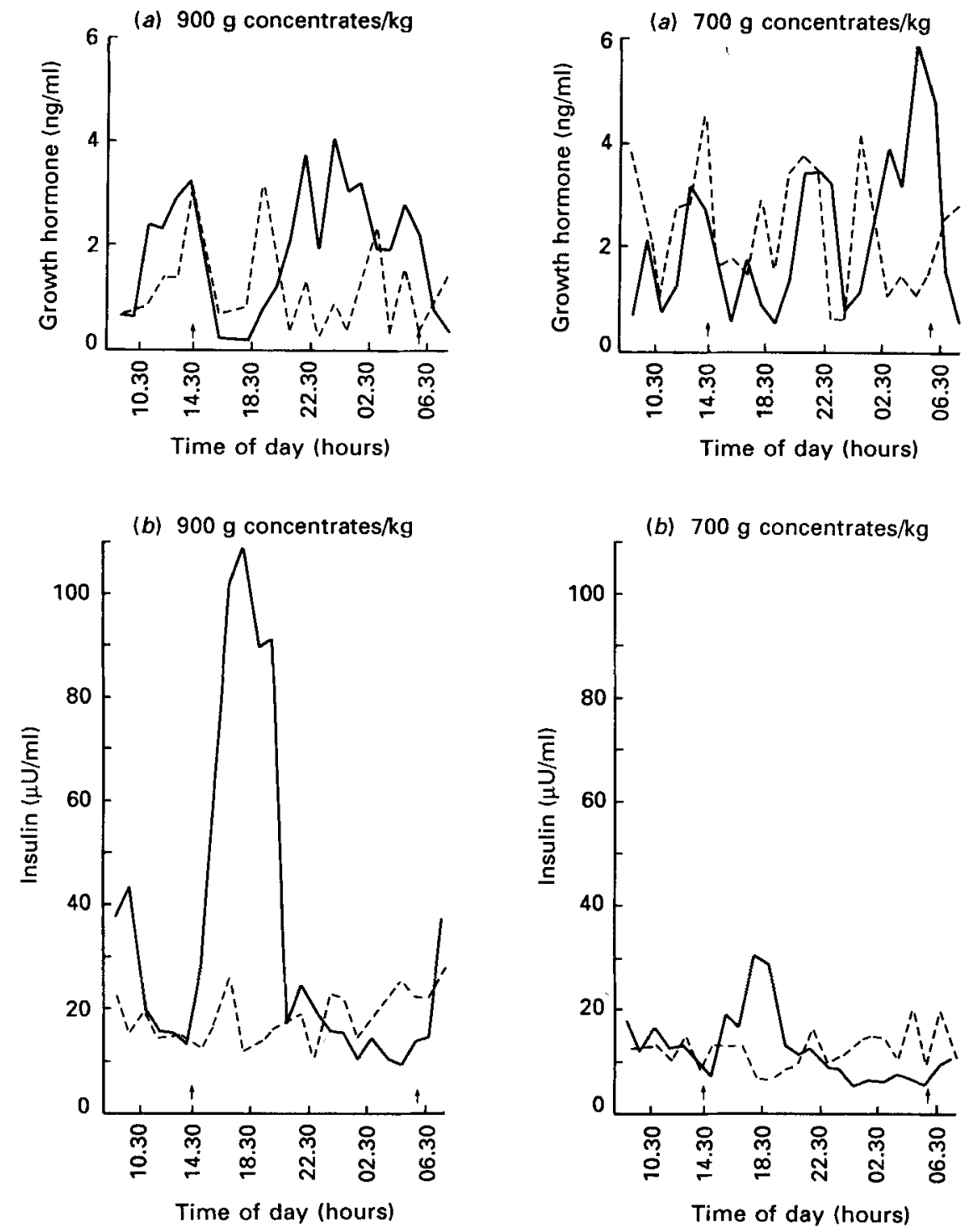

Fig. 2. For caption, see facing page.

higher for the higher concentrate diet than that for the lower concentrate diet but no clear response to type of diet was established for acetic acid or 3HBA.

Values for $n$-butyric acid were more variable than those for the other acids and no clear effect of treatments was established, but the diurnal pattern of concentration in the animals fed twice daily was very similar to that for the other acids.

\section{Plasma hormones}

The concentration of growth hormone in individual animals varied widely over the day for both feeding frequencies and both diets and no differences due to treatments were established for either maximum or minimum concentrations. In early and mid-lactation, 
(c) $900 \mathrm{~g}$ concentrates $/ \mathrm{kg}$

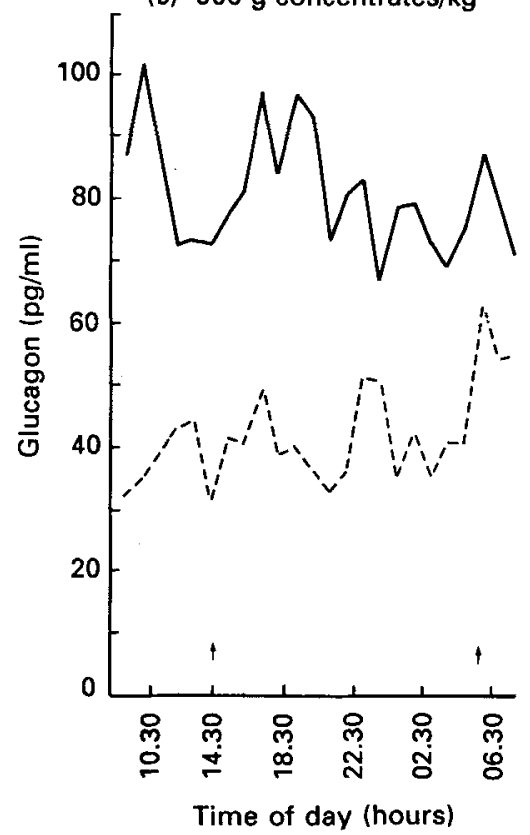

(c) $700 \mathrm{~g}$ concentrates $/ \mathrm{kg}$

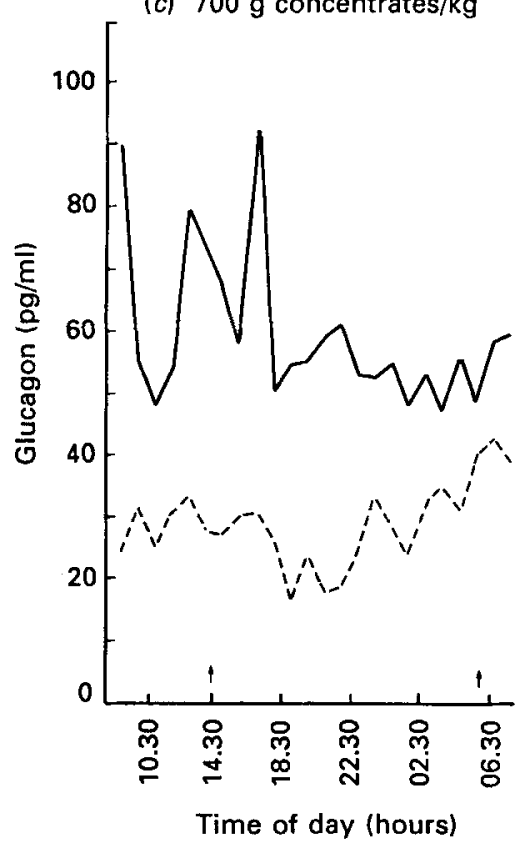

Fig. 2. Concentrations over $24 \mathrm{~h}$ of certain hormones measured at about week 22 of lactation in the jugular blood of lactating cows given two diets $(900$ or $700 \mathrm{~g}$ concentrates $/ \mathrm{kg}$ ) twice daily (-) or in six meals daily (---). (a) Growth hormone, $(b)$ insulin, $(c)$ glucagon. Feeding times are shown for six times daily feeding on the $x$ axis and for twice-daily feeding as arrows. Results are the means for four cows per treatment.

average minimum concentrations were 1.7 and 0.2 (SE 0.25$) \mathrm{ng} / \mathrm{ml}$ respectively and maximum concentrations were 11.8 and $6.8(\mathrm{SE} 0.90) \mathrm{ng} / \mathrm{ml}$ respectively. However, with twice daily feeding there was a tendency for the maximum and mean concentrations to be considerably reduced after each meal. This was particularly evident with the higher concentrate diet where the mean concentration was 6.7 (SE 0.73 ) $\mathrm{ng} / \mathrm{ml}$ for the $3 \mathrm{~h}$ before each meal and $2.2(\operatorname{SE~} 0.25) \mathrm{ng} / \mathrm{ml}$ for the period between 2 and $4 \mathrm{~h}$ after each meal in early lactation and 2.5 (SE 0.40$)$ and 0.4 (SE 0.09$) \mathrm{ng} / \mathrm{ml}$ respectively in mid-lactation. For the lower concentrate diet, the response was less consistent and the values before and after each meal were 7.2 (SE 1.19$)$ and $5.9(\mathrm{SE} 1.33) \mathrm{ng} / \mathrm{ml}$ respectively in early lactation and 3.3 (SE 0.55 ) and 1.1 (SE 0.33$) \mathrm{ng} / \mathrm{ml}$ respectively in mid-lactation.

With twice daily feeding, there was a clear pattern in insulin concentrations with peaks occurring 3-4 $\mathrm{h}$ after each meal, the peaks being higher after the afternoon meal than after the morning meal (Fig. 2). They were also higher with the higher concentrate diet with average maximum values of $112 \mu \mathrm{U} / \mathrm{ml}$ on high-concentrates and $31 \mu \mathrm{U} / \mathrm{ml}$ on lowconcentrates (SE 11.3). More frequent feeding greatly reduced the maximum concentration and the range with the higher-concentrate diet but had much less effect with the lowerconcentrate diet. Average maximum concentrations with frequent feeding were 32 and 22 (SE 11.3) $\mu \mathrm{U} / \mathrm{ml}$ for the higher and lower concentrate diets respectively, the interaction between feeding frequency and concentrate: hay ratio being highly significant $(P<0.001)$. More frequent feeding had only small effects on minimum concentrations.

The effects of meal frequency on glucagon concentrations were inconsistent (Fig. 2). Statistically the maximum concentration $(P<0.01)$ and the range $(P<0.05)$ were higher 
with twice daily feeding but results were not consistent and there was no clear pattern in relation to feeding time.

The effect of meal frequency and diet composition on the minimum and maximum concentrations of prolactin and thyroxine were small and inconsistent and no pattern in relation to time of feeding was apparent for either hormone.

\section{DISCUSSION}

Previous studies of the causes of milk-fat depression induced by low-roughage diets have concentrated on mean daily concentrations or production rates of metabolites and hormones and have not considered the possible significance of the pattern of changes in digestion and metabolism following a meal. This aspect will be examined in the cows fed twice daily in the present experiment and the results will then be contrasted with those found in the cows fed more frequently, to try to provide a more satisfactory explanation for the effect of meal frequency on milk-fat production.

The concentrations of acetic acid, propionic acid, 3HBA and insulin showed clear increases following feeding when both diets were given in two meals daily. The increases in the concentrations of the acids were obviously a direct consequence of the fermentation of the feeds in the rumen and were probably the principal cause of the increase in the concentration of insulin (Bassett, 1972; Ambo et al. 1973; Istasse et al. 1987). The increases in concentrations of propionic acid and insulin, but not of the other acids, were greater with the higher concentrate diet, supporting the suggestion of Bines \& Hart (1984) that propionic acid is the principal metabolite stimulating insulin release in cattle. The tendency for glucose concentration to fall after feeding probably reflected the increase in insulin concentration at that time.

There was clear evidence that the secretion of growth hormone was suppressed for a period of about $3 \mathrm{~h}$ following a meal with the high-concentrate diet given in two meals daily, but this response was less consistent with the low-concentrate diet. Other experiments have also shown that feeding suppresses growth hormone release in some circumstances but not in others (Bassett, 1972; Hove \& Blom, 1973; Bines et al. 1983). The reasons for the variability in response remain unclear. The postprandial suppression has been related to both physical (Tindal et al. 1985) and metabolic (Hove \& Blom, 1973) factors. The greater suppression with the diet containing the higher proportion of concentrates in the present experiment suggests that metabolic factors were predominant in this experiment.

Various theories have been advanced to explain the depression in milk-fat concentration caused by feeding low-roughage, high-starch diets. The one receiving the most consistent support is that such diets increase insulin secretion, probably because of high production rates of rumen propionate, and that the insulin increases adipose tissue lipogenesis at the expense of milk-fat synthesis (Annison, 1976). The results for the cows fed twice daily, presented in the previous paper (Sutton et al. 1986), supported this theory. With the higher level of concentrates, the proportion of propionic acid in the rumen VFA and the mean concentrations of propionic acid and insulin in peripheral blood were all higher. The present results show that, in addition, the maximum concentration and the daily range in concentration of both propionate and insulin in peripheral blood were also higher.

Of the lipid metabolites measured in the present experiment, the mean concentrations of acetic acid and 3HBA were lower with the high-concentrate diet while the mean concentrations of butyric acid and NEFA were not consistently affected (Sutton et al. 1986). Similar results were reported by Annison et al. (1974) who additionally found that, although the concentrations of NEFA and triglycerides were not reduced by a low- 
roughage diet, the entry rates of NEFA in the peripheral circulation and the uptake by the udder of acetate, 3HBA and triglycerides were all reduced.

The suppression of growth hormone release in the crucial postprandial period with the higher concentrate diet in the present experiment may also have contributed to milk-fat depression. One of the various effects of growth hormone is to increase adipose tissue lipolysis. A suppression of growth hormone secretion simultaneously with an increase in insulin would tend to reinforce the emphasis on lipid synthesis in adipose tissue at the expense of milk fat.

It is now necessary to consider whether the higher milk-fat concentration induced by more frequent feeding of concentrates can be explained in terms of any of these mechanisms. In the previous paper (Sutton et al. 1986) it was concluded that increasing meal frequency did not cause major changes in the mean daily rates of production of VFA in the rumen or their mean concentration in peripheral blood. However, the present results showed that more frequent feeding reduced both the maximum concentrations and daily range in concentrations of the VFA, 3HBA and insulin in peripheral blood particularly with the higher-concentrate diet, but there were no changes in these measures of the concentrations of the other hormones.

These results suggest that the severity of milk-fat depression caused by feeding lowroughage, high-starch diets in two meals daily reflects the concentration of VFA production into a short period after each meal. The resulting sharp increase in propionate production in the rumen causes insulin secretion to increase simultaneously and, in extreme cases, growth hormone production is temporarily inhibited. The hormone responses result in a reduction in lipolysis and increase in lipogenesis in adipose tissue coincident with the maximum availability of nutrients from the gut, thereby contributing to reduced milk-fat synthesis. With frequent feeding, the products of rumen fermentation are absorbed at a more constant rate and the fluctuations in the concentrations of insulin (Istasse et al. 1987) and growth hormone are reduced or, if not reduced, do not coincide with a major influx of nutrients from the gut. In consequence the severity of milk-fat depression is greatly reduced.

This conclusion regarding the significance of fluctuations in certain hormones in terms of milk-fat production appears to conflict with the conclusion of Bines et al. (1983) that "the mean concentrations (of insulin and growth hormone) over the $24 \mathrm{~h}$ period are of much greater importance in the regulation of energy partition than are the short-term fluctuations in response to feeding'. However, the conclusions from the present experiment refer specifically to the situation of milk-fat depression induced by dietary manipulation whereas Bines et al. (1983) were concerned with the more general change in energy partition associated with stage of lactation and breed of cow.

The authors are grateful to Messrs D. J. Napper and R. A. D. Hora for skilled technical assistance. Part of this work was commissioned by the Ministry of Agriculture, Fisheries and Food.

\section{REFEREN CES}

Ambo, K., Takahashi, H. \& Tsuda, T. (1973). Tohuku Journal of Agricultural Research 24, 54-62.

Annison, E. F. (1976). In Principles of Cattle Production, pp. 169--199 [H. Swan and W. H. Broster, editors]. London: Butterworths.

Annison, E. F., Bickerstaffe, R. \& Linzell, J. L. (1974). Journal of Agricultural Science, Cambridge 82, 87-95.

Bassett, I. M. (1972). Australian Journal of Biological Sciences 25, 1277-1287.

Bines, J. A. \& Hart, I. C. (1984). Canadian Journal of Animal Science 64, Suppl. 304-305.

Bines, J. A., Hart, I. C. \& Morant, S. V. (1983). Hormone and Metabolism Research 15, 330-334.

Hove, K. \& Blom, A. K. (1973). Acta Endocrinologica 73, 289-303. 
Istasse, L., Hovell, F. D. DeB., MacLeod, N. A. \& Grskov, E. R. (1987). Livestock Production Science 16, 201-214.

Kaufmann, W., Rohr, K., Daenicke, R. \& Hagemeister, H. (1975). Sonderheft der Berichte über Landwirtschaft 191, 269-295.

Sutton, J. D., Broster, W. H., Napper, D. J. \& Siviter, J. W. (1985). British Journal of Nutrition 53, 117-130.

Sutton, J. D., Hart, I. C., Broster, W. H., Fulford, R. J. \& Schuller, E. (1986). British Journal of Nutrition 56, 181-192.

Tindal, J. S., Blake, L. A., Simmonds, A. D. \& Hart, I. C. (1985). Journal of Endocrinology 104, $159-163$. 